\title{
The Significance of Costs Calculation in Evaluation of the Value Added*
}

\author{
Ewa Kulińska \\ Opole University of Technology, Faculty of Economic and Management, Opole, Poland
}

\begin{abstract}
In the article, a problem of importance of proper costs calculation caused by risk factors which emerge in logistic processes is presented. On the basis of literature analysis, there was shown the costs structure of the value chain. The concept of customer value and the concept of enterprise value were extracted. It presents also dependence between actions in internal value chain and generated cash flows. It signalizes also the meaning of risk management influence on the problem of achieving established value added, understood as net income from operational activity by the main enterprises processes. Basis of theoretical modeling using the Gorbatov's principle of characterization was discussed. The research material relates to food businesses. The study was conducted on the basis of questionnaires, surveys, and direct conversations with employees. To build the model, the theory of characterization was used. Its essence is in the mutual interpretability model of the test object to the model structure. Mutual interpretability of models is achieved by selection of the proper functioning of the universal laws (expressed in the functional model) and the structural interpretation of the functional model, the one of representative character is Hasse diagrams. The functioning of the model is illustrated experiment research of the study. The results show the great importance of the correct calculation of the cost of risk factors in logistics processes. Not taking into account the actual cost of risk factors may have a significant influence on errors in decision-making, giving an incorrect picture of the financial situation. A false idea of the creation of value-added may consequently result in the deterioration of the conditions of the enterprise market functioning.
\end{abstract}

Keywords: logistic process, risk factors, value added, principle of characterization, parametrization model, costs, total costs

\section{Introduction}

The value added is one of the key parameters to assess the efficiency of the enterprises. Analyzing the activities of the organization should always wonder what the added value is, where it comes from, what determines it, and what to do to make it as high as possible in terms of the entire process chain. The added value creation and the manner of its use in the creation of the new strategy is one of the main problems to solve.

The company independently determines the value that will be provided in the form of a product which it has decided to produce. Clients represent a demand for what the company offers. From these premises, certain

\footnotetext{
* Research funded by the National Science Centre in the project 2012/05/B/HS4/04139.

Ewa Kulińska, Associate Professor, Head of Department of Marketing and Logistics, Faculty of Economic and Management, Opole University of Technology.

Correspondence concerning this article should be addressed to Ewa Kulińska, Faculty of Economic and Management of Opole University of Technology, Luboszycka 7 Street, 45-036 Opole, Poland. E-mail: e.kulinska@ po.opole.pl.
} 
consequences are derived. A way to interact with customers through the process of exchange is needed, in order to sell products. The way businesses interact with customers has long been a method enabling it to obtain economic value from the customer. Companies have developed different procedures for obtaining this value - by increasing the range of products offered, efficient delivery and servicing products, adapting them to the needs of individual customers, and many other. One of the most important is the continuous improvement of the processes. A number of possibilities associated in this respect with the concept of risk management. Planning, organization, implementation, and control of interference in the course of logistics processes contribute to creating a higher level of realized customer value and higher added value for the company. The analysis of the literature was developed based on the publications of recognized authorities (Bowersox, 1987; Cooper \& Ellram, 1993; Giunipero \& Brand, 1996; Hewitt, 1994; Jenkinson, 1995; Johnson \& Wood, 1993; Porter, 1985; Prahaland \& Ramaswamy, 2005; Schuderer, 1996).

The paper presents the author's studies intended to demonstrate that proper costing of risk factors in logistics processes significantly reflected in the assessment created by a value added. Model proposed by the author translates directly into increased opportunities measureable change in value added induced by the implementation of the risk management system.

For the modeling there were used solutions based on the algebra of logic and Gorbatov's principle of characterization. The resulting model structure and model of the verified during research yielded results in the form of a solution to the quantification of the total and the actual cost of risk factors in logistic processes and the assessment of change in value added.

\section{Theory and Research Problems}

Level of utility which is given to a client by results of process realization, in practical sense, is not measurable. Utility itself has subjective character and is an abstractive category. All attempts to impute a unit to it (e.g., utyl) failed. Utility can by ascribed with the ordinal only. In that meaning utility is the reflection of orderly preferences system.

It is however crucial category in analyzing value added that realized by enterprise's processes. Without any value for the client, there is, in fact, no value for the enterprise either-those are interdependent. The real value added may emerge only when client purchase product and founds come in to bank account of the enterprise.

As Figure 1 shows that dependence between value for a client and value for an enterprise is also dependent on the exchange. On the one hand, there is the money transfer, which is the value within the meaning of the revenue for the enterprise; and on the other hand there is the transfer of the stream of products, which constitute the value within the meaning of benefits and utilities for the buyer.

It is on the basis of these two relations, which can be seen in Figure 1, that it is possible to define the value added as the difference between revenues from sales of products and their manufacturing $\operatorname{costs}\left(V_{x_{f}}-V_{i, f}\right)$ in economic terms or as the surplus of the utilities received by the buyers $\left(V_{i, c}\right)$, which are expressed by the willingness to pay (covering the costs) for the product $\left(V_{x, c}\right)$ in terms of market value. If it can perceive the created value as the buyer propensity for paying for the product of the given enterprise (Porter, 1985) then the economic value corresponds with the market value (with the utility).

In accordance to the fact that benefits and utilities for a client are not measurable, the relation between them and costs can not be described as formal relation (formula). Therefore it can not assume as a real part of 
interpretation doing from Figure 1. In aspect of the value for an enterprise, relations between income and costs can be described as difference or quotient. Each enterprise should endeavor to the situation when such difference is positive and possibly the highest. The higher than 0 result of quotient is, the higher level of the value added gained by enterprise is.

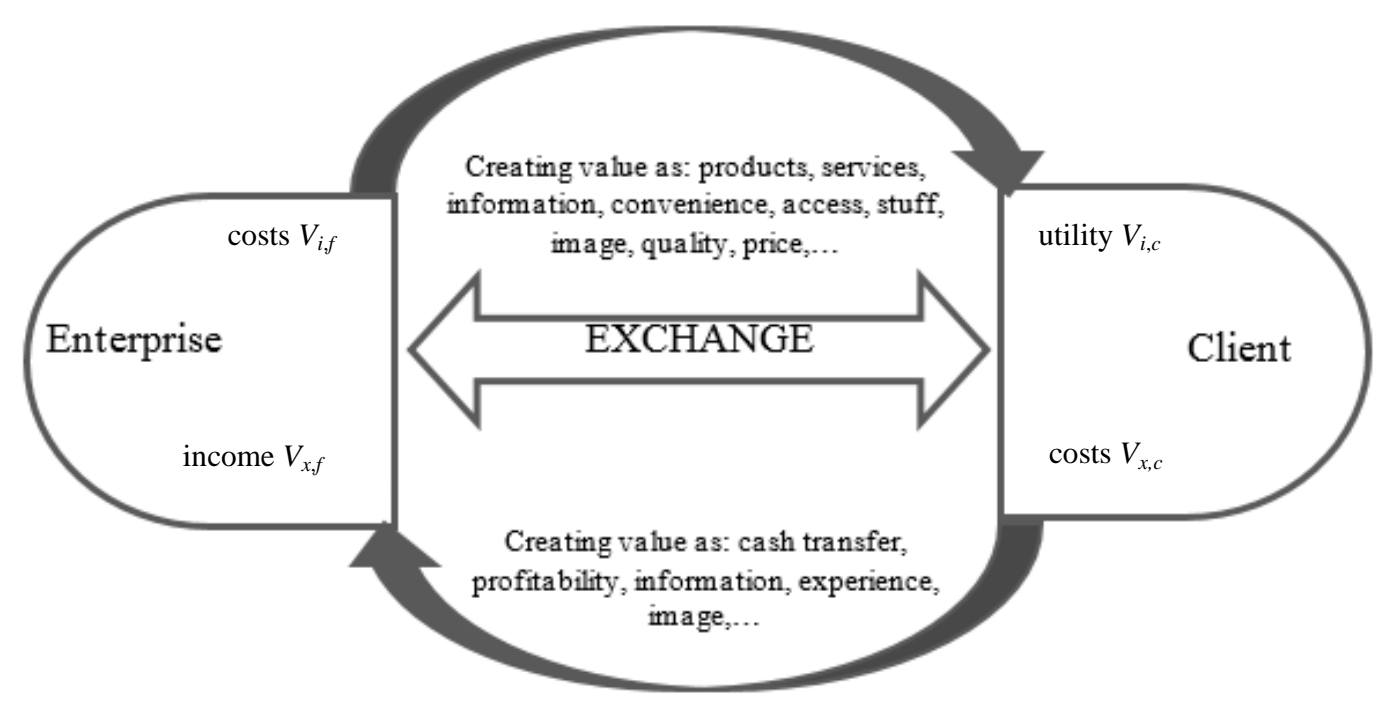

Figure1. Exchange-value for a client and for an enterprise. Source: Own elaboration on the basis of Porter, 1998, p. 38.

The interpretation of Porter implies two depictions of the value category (Porter, 1998). The first one is shown as a sum of costs incurred in relation to production of the given product. The second one is shown in terms of the exchange value as the price that the buyer is willing to pay for the product. Without taking into account the relation client-enterprise in the first term, it could come to the conclusion, that increasing expenditures for achieving process result, which is a product, would increase its value. That is not true, even significant increase of total costs related to article production does not guarantee an increase of its value, that value may stay unchanged or even decrease.

In second term, considering that value is a price which clients are willing to pay for the result of a process, could be even more doubtful. That would mean that increase of the price implies increase of the value of process result for a client, which is not true either.

From the point of view of the enterprise, considering the customer value and activities creating this value makes sense, if the categories mentioned above are treated as carriers of revenue. It is possible to assume in this way that there is a certain level of the customer value, at which the value for the enterprise is the largest.

While interpreting this relationship, one should assume that performing activities creating the customer value causes the rise in sales revenues, since the improvement in parameters (quality, amount and the like) of the product causes that the customer is willing to pay extra for it. However, if the action in favor of the product does not contribute to the increase in its value in the form of the rise in the income but causes the increase in costs then it is an activity not creating value.

It is because, as indicated at least by the value chain concept, the key objective of any company is to maximize the value for owners rather than for customers. 
The value chain is important instrument for analyzing value added for an enterprise. Realization basic processes with participation supporting processes determine flow of cash, which decides abort creating value for an enterprise (economic value).

In Table 1 there was shown dependence between individual activities in internal value chain and generating cash incomes. Set of activities comprising on value chain processes determines level of individual constituent categories of stream of the flow of cash, so that it determines level of value for an enterprise (Kulińska, 2009a).

Table 1

The Relation Between the Customer Value and the Value for the Enterprise

\begin{tabular}{|c|c|c|c|c|c|}
\hline \multicolumn{6}{|c|}{ Enterprise infrastructure } \\
\hline \multicolumn{6}{|c|}{ Human resources management } \\
\hline \multicolumn{6}{|c|}{ Technology developement } \\
\hline \multicolumn{6}{|c|}{ Butying } \\
\hline $\begin{array}{l}\text { Logistics of } \\
\text { entrance }\end{array}$ & Production & $\begin{array}{l}\text { Logistics of } \\
\text { withdrawal }\end{array}$ & Marketing and sell & $\begin{array}{l}\text { After selling } \\
\text { services }\end{array}$ & \\
\hline & & & & & Sell income \\
\hline \multirow[t]{2}{*}{$\begin{array}{l}\text { supplies storage } \\
\text { administration } \\
\text { material } \\
\text { manipulation }\end{array}$} & $\begin{array}{l}\text { tooling } \\
\text { installation } \\
\text { testing } \\
\text { packing }\end{array}$ & $\begin{array}{l}\text { storage } \\
\text { distribution } \\
\text { administration } \\
\text { material } \\
\text { manipulation } \\
\end{array}$ & $\begin{array}{l}\text { sell } \\
\text { advertising } \\
\text { promotion } \\
\text { administration }\end{array}$ & $\begin{array}{l}\text { installation } \\
\text { tutorials } \\
\text { maintenance } \\
\text { returns }\end{array}$ & operating costs \\
\hline & & & & & $\begin{array}{l}=\text { operating income }- \\
\text { income tax = } \\
\text { operating income } \\
\text { after taxation }+ \\
\text { amortization }\end{array}$ \\
\hline \multirow[t]{2}{*}{$\begin{array}{l}\text { inventories of raw } \\
\text { materials for the } \\
\text { production of } \\
\text { liabilities }\end{array}$} & $\begin{array}{l}\text { undone production } \\
\text { of liabilities }\end{array}$ & $\begin{array}{l}\text { inventories of } \\
\text { finished products }\end{array}$ & charges & $\begin{array}{l}\text { inventory of spare } \\
\text { parts }\end{array}$ & $\begin{array}{l}+/- \text { change in } \\
\text { demand for } \\
\text { networking material }\end{array}$ \\
\hline & & & & & $\begin{array}{l}=\text { flows of cash from } \\
\text { operating activity }\end{array}$ \\
\hline $\begin{array}{l}\text { stores } \\
\text { warehouses } \\
\text { transport cars } \\
\text { equipment }\end{array}$ & $\begin{array}{l}\text { production facilities } \\
\text { tools and machines } \\
\text { needed for } \\
\text { production }\end{array}$ & $\begin{array}{l}\text { stores } \\
\text { warehouses } \\
\text { transport cars } \\
\text { equipment }\end{array}$ & $\begin{array}{l}\text { facilities for } \\
\text { distribution } \\
\text { cars of sales } \\
\text { representatives } \\
\text { computers and other } \\
\text { devices }\end{array}$ & $\begin{array}{l}\text { service facilities } \\
\text { transport cars } \\
\text { equipment and } \\
\text { service devices }\end{array}$ & $\begin{array}{l}\text { - investments in } \\
\text { fixed assets }\end{array}$ \\
\hline & & & & & $=$ value added \\
\hline
\end{tabular}

Note. Source: Elaboration on the basis of Kulińska, 2011.

It is important to identify cost creating factors in the enterprise and examine their impact on the creation of the value added. The analysis of the internal value chain of the enterprise should be carried out, that is:

- The activities performed in the areas of individual groups of functions should be recognized;

- The analysis of the relations occurring amongst these actions in different sections should be along with assigning costs, revenues, and assets to these actions;

- The identification of factors affecting the level of costs should be conducted.

The last stage concerns the use of this information in order to determine the strategy and possible modifications to the chain (Kulińska, 2009a). Research using the enterprise value chain taking into account 
cash flows is relatively difficult, which results from the analysis of literature and studies. Problems arise from the need to obtain the information necessary for the various stages of analysis. This means the need of excluding logistic costs from overheads in the accounting system. These obstacles most often appear in the following situations:

- When the company has no separate individual processes and, consequently, does not recognize them as a separate organizational areas to gather information and generate cost;

- The accounting is tailored to the functional organization of the company and not to the horizontal;

- If the organization assumes the independence of internal accounting one enterprise, and information, related to the coordination of various processes, are rarely collected;

- The accounting system takes into account the ongoing relationship between indoor units the company, but uses the off, not basic, simplest means of accounting for the shape of interdependence.

It is because of the obstacles mentioned above that the method does not have many supporters. If additional deviations, which may appear in the course of logistic processes, are taken into account, its implementation seems to be almost impossible.

The risk management process can be interpreted as a component of the transformation process in logistics processes, the aim of which is to achieve the highest value. It is an inherent component of the transformation in the process of creating customer value and added value for sized enterprise.

The risk management process is shown in Figure 2 as supporting the transformation process by translating the likelihood and consequences of risk factors in logistics processes. The achievement of the objectives in this respect can be seen in two directions. On the one hand, the identification and assessment processes in terms of added value are of vital importance in the design of integrated risk management system, on the other hand, optimally designed system integrated risk management directly translates to the level of the creation of value (Kulińska, 2009b).

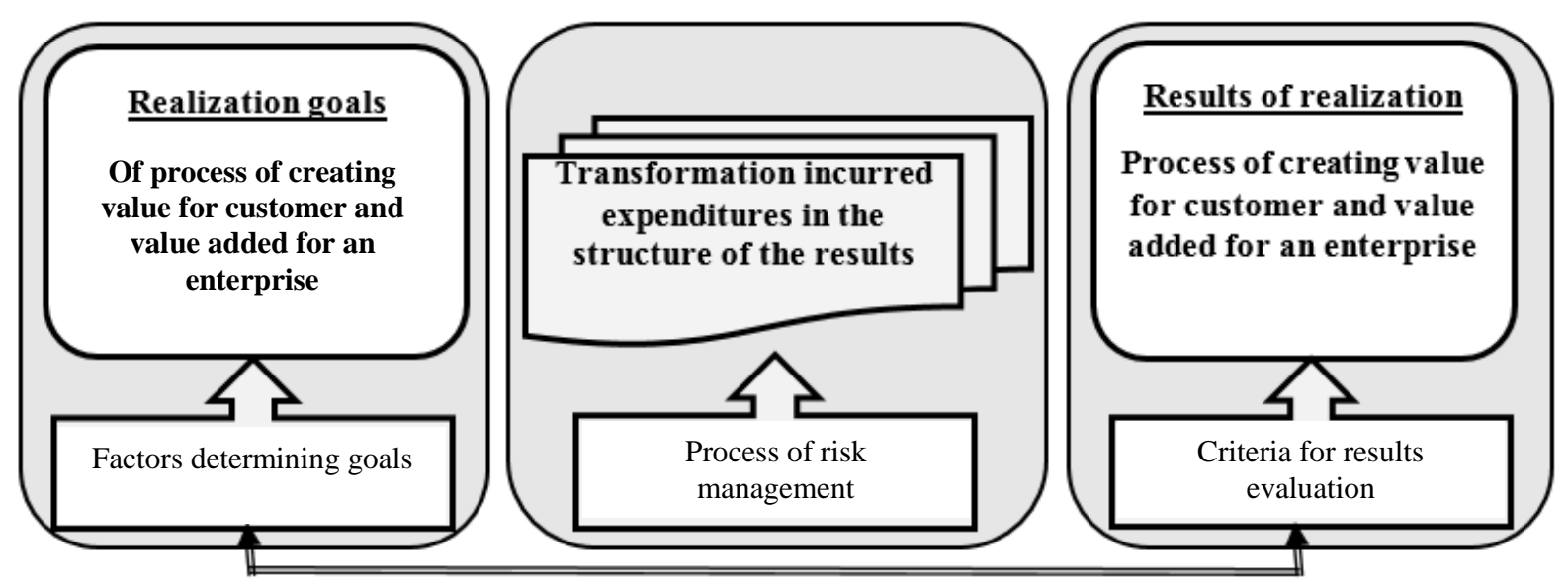

Figure 2. Risk management as an inherent component of the transformation processes of value creation.

The first aspect of the relationship between risk management and value creation of logistic processes associated with the division of logistics processes in terms of their contribution to the creation of added value. The second one points to the fact, that the more developed risk management system, the greater the increase in the value added obtained in the results process - that means in products. 


\section{Research Problem in Terms of Functional and Structural Characterization Principle}

In the context of its deliberations process should be interpreted as a statement of successive steps, repeated in a certain cycle that transform input resources in the outcome of the process. The transformation consists in giving a new value (value added). Measurable objective is to obtain as a result of the highest value-added verified and recognized by the recipient.

This approach facilitates the optimization of the enterprise as a whole, because the boundaries between departments, to communication, are replaced by boundaries between processes. As a result, the overriding objective is the result of the process, and what processes and their results are expected source of delivery to the customer by their products. Logistics processes are to help improve the management system and ensure its effectiveness and efficiency. They include activities and activities related to the preparation of the structure of the basic processes, creating management information systems, transportation, storage, finance and accounting, reporting and controlling.

Logistics processes do coordinate all the activities carried out in the enterprise. The final objective is to achieve unanimity coordination in the implementation of the tasks, which are components of these activities. The key to coordination is an insight into the internal structure of the performers and their tasks. Logistics processes appear when there is a need to coordinate with each other main processes carried out in a manufacturing company.

Structural and functional nature of the relationships in logistics processes indicates the possibility of using the rules for parameter characterization of their added value. Analyzing the impact of risk factors in logistics processes at the level of added value produced, there is a need to simultaneously take into account parameters such as (Kulińska, 2011):

- The process of value creation;

- Identification of risk factors;

- Probability (frequency) of risk factors;

- The effects caused by risk factors;

- Depending logical, time, priority, hierarchical, functional;

- The conditions of the transformation;

- Input (supply) processes;

- Output (the effect of implementation) processes;

- The result of the implementation process.

Given the multitude of possible states that these parameters can take, there is a situation, which implies the necessity to generate and evaluate a set of many possible solutions that may occur in a particular problem situation. As the number of elements of the set of the solutions for most practical problems grows in the NP-complete way, there is no practical possibility of seeking and considering each of them in the real time. Hence, the need of seeking solutions appears, which could enable the selection of variants to be evaluated and allow for narrowing the space and reducing the time of finding interesting solutions.

Principle of characterization belongs to modern methodology apparatus of system theories. Systemic interpretation of tasks in accordance to that principle boils down primarily to the:

(1) Designation not the solutions themselves, but its characteristic features;

(2) Features of solutions should refer to representatives (invariants) of equivalence class of solutions; 
(3) Equivalence class of solutions emerges as a result of interpretation of input the dissolved group of tasks in terms of the characteristics of solutions.

Equivalence classes of solutions are usually less than all possible solutions and the analysis of the characteristics of solutions can be carried out without the direct (present) generation. Developed formally and methodologically verified in the area present rules of characterization, form a theory of characterization. Its essence lies in the mutual interpretability model of the test object to the model structure. Mutual interpretation-ability models are achieved by selection of the proper functioning of the universal laws (expressed in the functional model) and the structural model of interpretation (Gorbatov, 1979).

In accordance with the principle of characterization, facility will function properly if you manage to define and prove mutually consistent interpretation of the rules among its functioning (described by the model of which is denoted by $\psi_{a}$ ) and the structure of executing (described by the model structure which is denoted by $\left.\psi_{b}\right)$. To define and prove unambiguous interpretation of these two models, here are the following assumptions:

- Resource is functioning adequately to its structure;

- The structure of the resource is adequate for the desired mode of functioning.

The essence of the principle of characterization can be written as:

$$
\left\langle\psi a, \psi_{b}, P_{0}\left(\psi_{a}, \psi_{\mathrm{b}}\right)\right\rangle
$$

where:

$\psi_{a}$-model of functioning;

$\psi_{b}$-model of structure;

$P_{0}\left(\psi_{a}, \psi_{b}\right)$-atomic predicate.

Atomic predicate $P_{0}\left(\psi_{a}, \psi_{b}\right)$ is characterized by the possibility of interpreting the model in terms of the functioning of $\psi_{a} \psi_{b}$ structure model. The predicate $P_{0}$ is a special case of the Boolean variable and takes the value " 1 " or " 0 ". " 1 " indicates the possibility of mapping, while "0" indicates the lack of such a possibility.

Application of the principle of characterization requires precise definition:

- What is the operating model of logistic processes?

- What is the structural model of logistic processes?

- How should the $P_{0}$ predicate be interpreted $\left(\psi_{a}, \psi_{b}\right)$ ?

Developing the theory of the conditions for converting the $\psi_{a}$ model into the $\psi_{b}$ model for construction parameterization model of logistic processes requires:

(1) The set of $\psi_{a}$ operating models in terms of logistic processes includes the information on:

- The probability (frequencies) of appearing of risk factors in logistic processes;

- The effects of appearing of risk factors (defined as the maximum cost caused by them, when they appear in logistic processes) as well as;

- The achieved (planned) value added, adequate for all examined manufacturing companies with regard to the period of the research (2012-2013).

(2) The set of the $\psi_{b}$ structural models in terms of logistic processes includes the information on:

- The continuity of the course of logistic processes supporting main processes in the manufacturing company;

- The real costs (the effects and the probability) of appearing of the defined risk factors in logistic processes;

- The achieved (real) level of the value added in the obtained outcome of the process adequate for all 
examined manufacturing companies with regard to the period of the research (2012-2013 flies).

(3) The $\mathrm{P}_{0}$ atomic predicate $\left(\psi_{a}, \psi_{b}\right)$ determines the mutual interpretability of the operating model in terms of the structural model (Kulińska, 2011).

To formulate a model of the necessary information is the frequency of risk factors in logistics processes. The presence of risk factors in the area of operation of the logistics processes in a given year in the operational model was designated as the first. If the risk factor did not occur in a given year in any area or function, has not been included in the propositional function (Kulińska, 2011).

It is on the basis of the data describing the probability and the effect of appearing of the risk factors in logistic processes for any manufacturing company that it is possible to develop an operating model in the form of the system of propositional functions, which describe relations and structure of logistic processes, i.e., such propositional functions, which will include the information on the presence of risk factors with the defined effect and probability in logistic processes and which affect the created value added in the given period of time here: month or year.

On this basis, it can be concluded that the model of functioning, contains information about the total cost of risk factors in logistics processes, because the data is mapping the current state of the research problem fixed on the basis of a specific company and a specific period of time.

In fact, the costs of the risk factors appearance are usually higher than the ones, which are shown in income statements. It is to obtain the information on the real costs caused by risk factors that an interpretation of the structural model is essential. Obtaining the structural model requires the accomplishment of the consecutive stages of the characterization principle.

The set of $\Psi_{b}$ structural models in terms of logistic processes must include information on the real costs of the presence of risk factors in logistic processes translating into the size of the value added achieved by the given company. It is achieving this result that requires, according to the characterization principle, determining conditions of redesigning the operating model into the structural model so as that its components would create a partially ordered set, i.e., the set whose elements $P_{i}^{\sigma i}$ meet the requirements of the partial ordering:

$$
R \subset P \times P\left(P_{i}^{\sigma i} \in P\right)
$$

Described with properties:

- Maneuverability:

$$
\forall\left(P_{i}^{\sigma i} \in M\right)\left[\left(P_{i}^{\sigma i}, P_{i}^{\sigma i}\right) \in R\right]
$$

- Antisymmetry:

$$
\forall\left(P_{i}^{\sigma_{i}}, P_{j}^{\sigma_{j}} \in M\right)\left\{\left[\left(P_{i}^{\sigma_{i}}, P_{j}^{\sigma_{j}}\right) \in R\right] \wedge\left[\left(P_{j}^{\sigma_{j}}, P_{i}^{\sigma_{i}}\right) \in R\right] \rightarrow P_{i}^{\sigma_{i}}=P_{j}^{\sigma_{j}}\right\}
$$

- Trazitivity:

$$
\forall\left(P_{i}^{\sigma_{i}}, P_{j}^{\sigma_{j}}, P_{k}^{\sigma_{k}} \in M\right)\left\{\left[\left(P_{i}^{\sigma_{i}}, P_{j}^{\sigma_{j}}\right) \in R\right] \wedge\left[\left(P_{j}^{\sigma_{j}}, P_{k}^{\sigma_{k}}\right) \in R\right] \rightarrow\left(P_{i}^{\sigma_{i}}, P_{k}^{\sigma_{k}}\right) \in R\right\}
$$

where:

$R$-relation symbol;

$P$ - set of risk factors; 
$P_{i}^{\sigma_{i}}, P_{j}^{\sigma_{j}}, P_{k}^{\sigma_{k}}$ - element sof risk factors set;

$\mathrm{M}$ - set of propositional variables.

The correct form of presentation of the model structure is the Hasse diagram, because it is directed graph, which captures the idea of the process as a sequence of consecutive steps at risk. Constructing a Hasse diagram requires the removal of all the graphical presentation of the process loop, which is repeated operations, mirrored (which corresponds to a set of partially ordered property maneuverability) and closing arches that reflect such incorrectly labeled internal transport routes, incorrect or lack of labeling storage boxes, etc. (which corresponds to the congregation partially ordered property of transitivity).

Finding the optimal Hasse diagram requires the transformation model of $\psi_{a}, \psi_{b}$ in the model structure in such a way that the propositional function stored in the model $\psi_{a}$ was clearly interpreted in the model $\psi_{b}$.

In the assumptions of the characterization theory, the universal laws of correct functioning are expressed by means of the so-called prohibited graph figures, defined as abstract structures, which should not appear in form of homeomorphisms in the operating model "under threat" of its incorrectness what originally was applied in the automata theory (Gorbatow, 1979; Nazaretow, Kim, \& Krupa, 1991).

The prohibited $Q^{A}$ figure is a graph submodel recorded in the form of cycle with odd length, whose apexes are weighed with pairs of cyclically changing weights, which are indexes of appropriate alternative elements. For model parameterization, such a graphic character indicates the presence of risk factors in more than one area of significance processes. It is very important from a point of view of the cost analysis concerning removing effects of the presence of risk factors, since the effects will be noticed in many areas (the number depends on a specific case) of functioning of any company and this will multiply costs and translate into a reduction in the value added in this way.

The second kind of the prohibited figure is the $Q^{B}$ figure, which is a graph submodel recorded in the form of the triangle with hanging vertexes. The vertices of the triangle have equal weight, and each of them has an additional weight equal to the weight hanging vertex.

This kind of a prohibited figure corresponds to the situation, when the risk factors present in one area affect the adjacent ones, e.g., a risk factor associated with transport (let's denote it as $a$ ) triggers a risk factor in supply (let's denote it as $b$ ) and simultaneously triggers a risk factor in production (let's denote as $c$ ) as well as in the area of distribution (let's denote it as $d$ ). It is removing the initiator, that is splitting the prohibited graph figure according to the characterization principle through splitting the factor " $a$ ", that will eliminate effects in four areas.

While splitting prohibited graph figures, one should take the following issues into account:

- The splitting should be carried out in such a way that all prohibited graph figures will be eliminated;

- It is out of possible variants of splits (replicas of variables) that we always choose the minimal subset of propositional variables, which will cause the elimination of all prohibited graph figures;

- It is to choose from possible variants of splitting propositional variables that it uses a semantic decision table;

- The choice of a variable/variables for splitting conditions the form of the new $\psi^{\prime}{ }_{a}$ operating model, and hence the form of the resultative Hasse diagram.

Obtaining a new model of operation and the particular form of the diagram Hasse has its consequences. The conducted operations are followed by splitting of the propositional variables. The meaning of the logistics 
process variables reflects the risk factors in the studied areas of logistics processes, characterized by a certain probability and effect of risk factors, e.g., mirroring actions translate into the final level of costs. By applying the principles of characterization in a simple way it can be seen that the presence of risk factors has its consequences not only at the site of the event, the effects often translate into other areas of the enterprise and even the entire organization. After successful characterization it is possible to calculate the real costs of the risk factors.

Application of the principle of characterization for the parameterization of logistic processes is primarily associated with the demonstration of the actual costs actually incurred in connection with the occurrence of certain risk factors in logistics processes. After this analysis, using the model parameter logistic processes can be demonstrated that the actual costs are higher risk than those included in the calculations (if any are reported). Absence from the real cost of risk factors may have a significant influence on the creation of added value, translating to the terms of the enterprise in the market.

\section{Research Design}

Driven by the demands of the principle of characterization, use of logistic processes:

- Makes a formal record of the studied fragment of reality in the form of the system of propositional functions;

- Develops an operating model of the studied fragment of reality, through the analysis of the function, the elimination of the forbidden graph figures from the model of the propositional function with the use of the semantic decision table as well as splitting the $\psi_{a}$ graph operating model;

- Finds its structural (technical) interpretation in the form of the graph structural model in the form of Hasse diagrams for the developed operating model.

Obtaining information on the actual costs incurred by the company in connection with the occurrence of risk factors showing structural-functional depending on the model, described in the example.

On the basis of data obtained from studies conducted in the years 2012-2013 in the food manufacturing set propositional function describing the risk factors in logistics processes translate into the creation of value added enterprises. Examined dozens of companies, the functioning of the model calculation is illustrated in one of the most representative of the surveyed companies located in the province of Opole in Poland.

Among the 67 identified risk factors for the analysis, nine of which were the most representative, and were selected. These include the risk factors $X_{7}, X_{8}, X_{23}, X_{30}, X_{46}, X_{49}, X_{52}, X_{60}, X_{67}$-which have been identified in six functional areas of business: procurement, production, distribution, transport, storage, and managing logistics processes. On this basis, the propositional function took the following form:

$$
\mathrm{ZP}_{\mathrm{x}}\left(X_{1}, X_{2}, \ldots, X_{67}\right)=X_{7} X_{49} X_{23} V X_{7} X_{52} V X_{30} X_{46} V X_{8} X_{46} X_{23} V X_{46} X_{60} X_{67} V X_{30} X_{52} X_{67}
$$

Each of the risk factors selected for the analysis $X_{7}, X_{8}, X_{23}, X_{30}, X_{46}, X_{49}, X_{52}, X_{60}, X_{67}$ includes information on the frequency (the probability) of appearances of risk factors as well as potential effect (measured with the maximum cost of removing the effects of the appearance of the risk factors). Taken into account the data of the company, these values were as follows (see Table 2).

On this basis, it can be determined that the operating model includes information on all-in costs of the presence of risk factors in logistic processes, since it is data mapping the direct information from the company examined in the given period of time. While limiting to these factors, it can be stated that the value added of the company could be higher by about PLN 7,515,332. On the annual basis of the operations of the company 
listed on the Warsaw Stock Exchange, it seems not to be a large amount but only a few risk factors are analyzed here.

Table 2

Statement of the Likelihood and Effect of Risk Factors Appearance in Function $Z P_{x}$

\begin{tabular}{|c|c|c|c|c|}
\hline \multirow{2}{*}{$\begin{array}{l}\text { The area of the appearance of } \\
\text { risk factors }\end{array}$} & \multirow{2}{*}{ Propositional variable } & \multicolumn{2}{|c|}{ 2012-2013 } & \multirow{2}{*}{ Quantity $\times$ cost } \\
\hline & & Quantity & Max cost & \\
\hline \multirow{3}{*}{ Supplies } & $X_{7}$ & 90 & 2,000 & 180,000 \\
\hline & $X_{49}$ & 49 & 5,100 & 249,900 \\
\hline & $X_{23}$ & 76 & 4,700 & 357,200 \\
\hline \multirow{2}{*}{ Production } & $X_{7}$ & 90 & 2,000 & 180,000 \\
\hline & $X_{52}$ & 180 & 5,200 & 936,000 \\
\hline \multirow{2}{*}{ Distribution } & $X_{30}$ & 159 & 1,500 & 238,500 \\
\hline & $X_{46}$ & 230 & 3,600 & 828,000 \\
\hline \multirow{3}{*}{ Transport } & $X_{8}$ & 161 & 1,800 & 289,800 \\
\hline & $X_{46}$ & 230 & 3,600 & 828,000 \\
\hline & $X_{23}$ & 76 & 4,700 & 357,200 \\
\hline \multirow{3}{*}{ Storage } & $X_{46}$ & 230 & 3,600 & 828,000 \\
\hline & $X_{60}$ & 121 & 4,150 & 502,150 \\
\hline & $X_{67}$ & 99 & 2,859 & 283,041 \\
\hline \multirow{3}{*}{ Management logistics processes } & $X_{30}$ & 159 & 1,500 & 238,500 \\
\hline & $X_{52}$ & 180 & 5,200 & 936,000 \\
\hline & $X_{67}$ & 99 & 2,859 & 283,041 \\
\hline$\sum$ & & & & $7,515,332$ \\
\hline
\end{tabular}

\section{Research Method-The Principle of Characterization in Research Experiment}

Functioning model $\psi_{a}$ of propositional function $Z P_{x}$ is given as a statement of:

$$
\psi_{a}=\left\langle M, R_{2}, R_{3}\right\rangle
$$

where:

$M$-set of propositional variables;

$R_{2}$ - set of relations defined by 2-element alternative units;

$R_{3}$ - set of relations defined by 3-element alternative units.

$$
\begin{gathered}
M=<X_{7}, X_{8}, X_{23}, X_{30}, X_{46}, X_{49}, X_{52}, X_{60}, X_{67}> \\
R_{2}=\left\{\left\{X_{7} X_{52}\right\}_{2},\left\{X_{30} X_{46}\right\}_{3}\right\} \\
R_{3}=\left\{\left\{X_{7} X_{49} X_{23}\right\}_{1},\left\{X_{8} X_{46} X_{23}\right\}_{4},\left\{X_{46} X_{60} X_{67}\right\}_{5}\left\{X_{30} X_{52} X_{67}\right\}_{6}\right\}
\end{gathered}
$$

The module enables to obtain a graphic form of the functioning model, which is shown in Figure 3.

The purpose of modeling is to model the structure, solving specific research problem, namely the search for the actual cost of risk factors in logistics processes, translated into a decrease in realized value added for the company. Obtaining a result requires constraints to the model structure so that the elements of $X_{i}$ form a partially ordered set, i.e., a set whose elements satisfy the relation of partial order. It is therefore prohibited to designate figures $Q^{A}$ and $Q^{B}$.

For the function $Z P_{X}$ there were identified three types of $Q^{A}$ forbidden figures and one prohibited type of figure $Q^{B}$. The next peaks of forbidden figures represent propositional variables that when appearing in conjunctions in a certain order, graphically form loops (see Figure 4). 


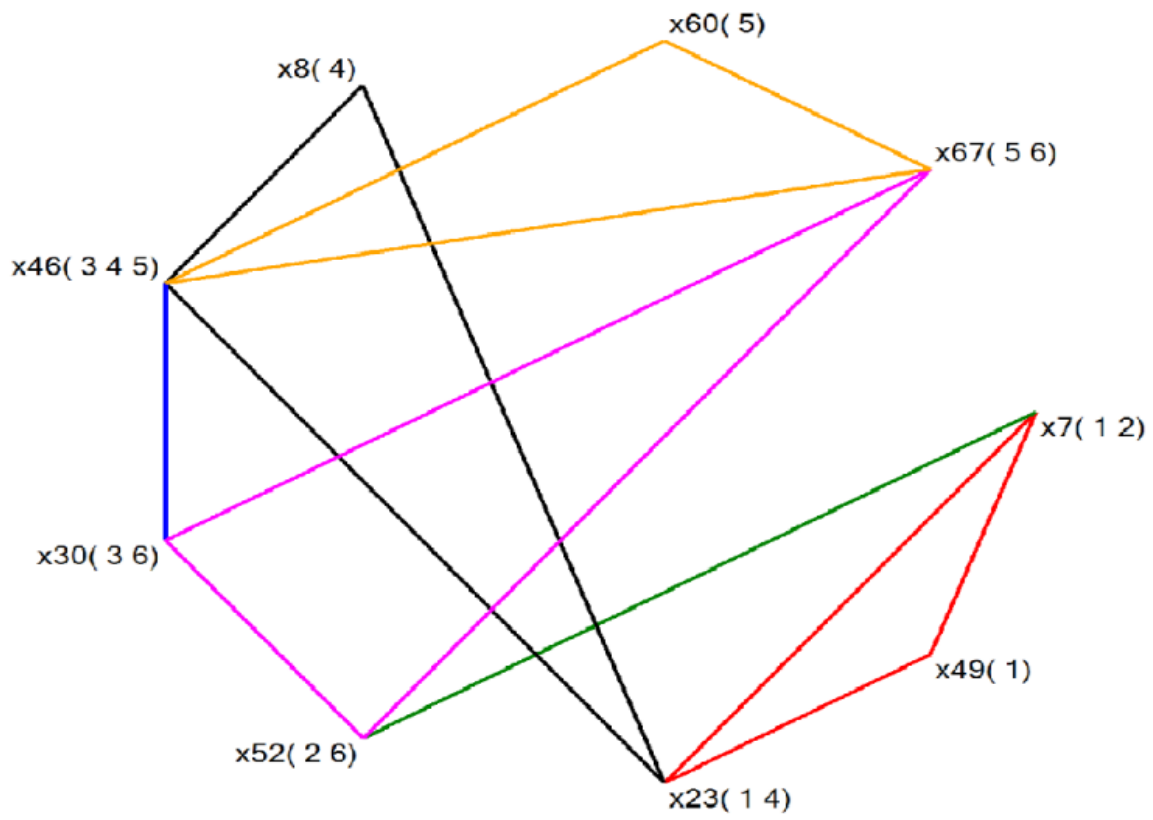

Figure 3. Functioning model $\psi_{a}$ of propositional function $Z P_{x}$.

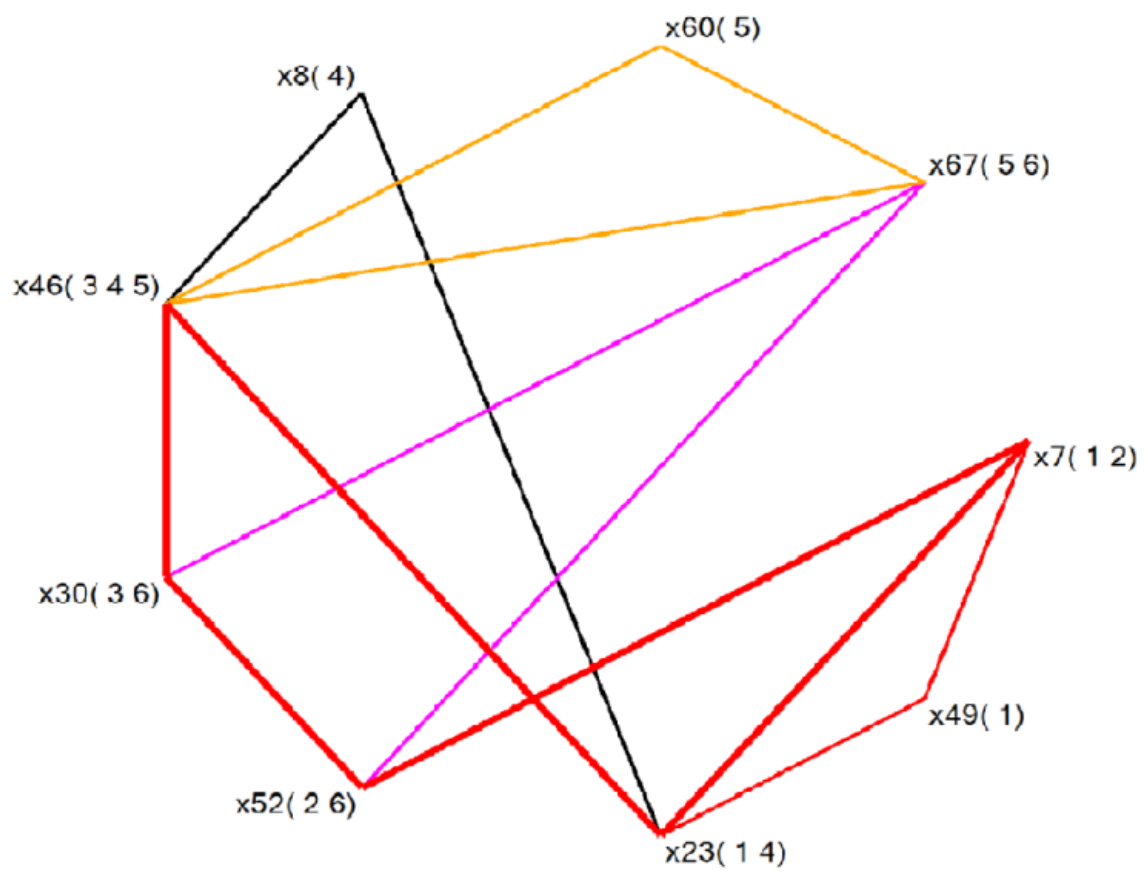

Figure 4. Counter model of functioning of function $Z P_{x}$ with marked prohibited count figure type $Q_{1}^{A}$.

The formal description of prohibited figure $Q_{1}^{A}$ :

$$
Q_{1}^{A}=\left\{X_{23}, X_{7}, X_{52}, X_{30}, X_{46}\right\}
$$

The second kind of prohibited figure is figure $Q^{B}$, which is counter submodel recorded in the form of a triangle with hanging vertices. Analyzed function also includes one figure of this type highlighted in Figure 5 with thick lines, and the peaks hanging by a dotted line. 


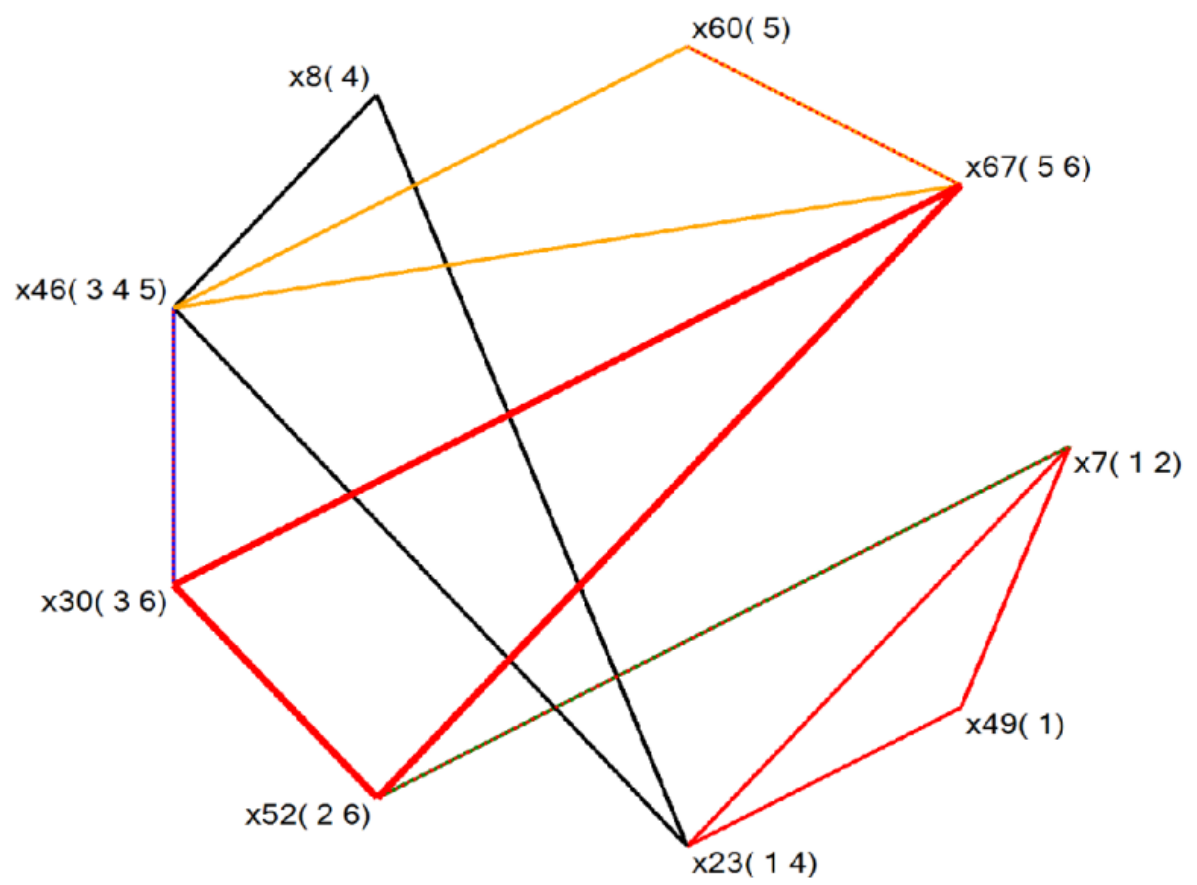

Figure 5. Counter model of propositional function $Z P_{x}$ with marked prohibited counter figure type $Q_{1}^{B}$.

The formal description of prohibited figure $Q_{1}^{B}$ :

$$
Q_{1}^{B}=\left\{X_{67}, X_{30}, X_{52}\right\}\left\{X_{67}, X_{60}\right\}\left\{X_{30}, X_{46}\right\}\left\{X_{52}, X_{7}\right\}
$$

For fission of prohibited figures which encountered in graph representation of the analyzed propositional function, there was an array of semantic (see Table 3).

Table 3

Array of Semantic Functions $Z P_{x}$

\begin{tabular}{lllllll}
\hline$Q_{1}^{A}$ & $X_{7}$ & $X_{23}$ & $X_{46}$ & $X_{30}$ & $X_{52}$ & $X_{67}$ \\
$Q_{2}^{A}$ & 1 & 1 & 1 & 1 & 1 & 0 \\
$Q_{3}^{A}$ & 1 & 1 & 1 & 0 & 1 & 1 \\
$Q_{1}^{B}$ & 0 & 0 & 1 & 1 & 0 & 1 \\
\hline
\end{tabular}

In the first row of the table, there were introduced propositional variables that occur in all the identified prohibited figures. The first column of figures while introducing prohibited. In the following lines numeral 1 denotes propositional variables as a vertex in a forbidden figure graphs that have occurred in the forbidden figure (see Table 1). Minimum subset of propositional variables that will eliminate all the figures prohibited choose guided by the frequency of occurrence of a propositional variable in the forbidden figures (the largest number of ones in the column of the array semantic), and from the point of view of the cost of logistics processes, among the alternatives, select the propositional variables that represent risk factors with the lowest probability (frequency) of occurrence and the lowest cost of potential effects occurrence.

Selection of variables condition will form a new model of $\psi^{\prime}{ }_{a}$, and thus form the resulting Hasse diagram 
and the level of the actual cost of picking risk factors in logistics processes translates into the level of the value added. Taking into account both criteria of fission it select variables $X_{46}$ and $X_{52}$. Splitting the two variables in conjunction first (see Figure 6).

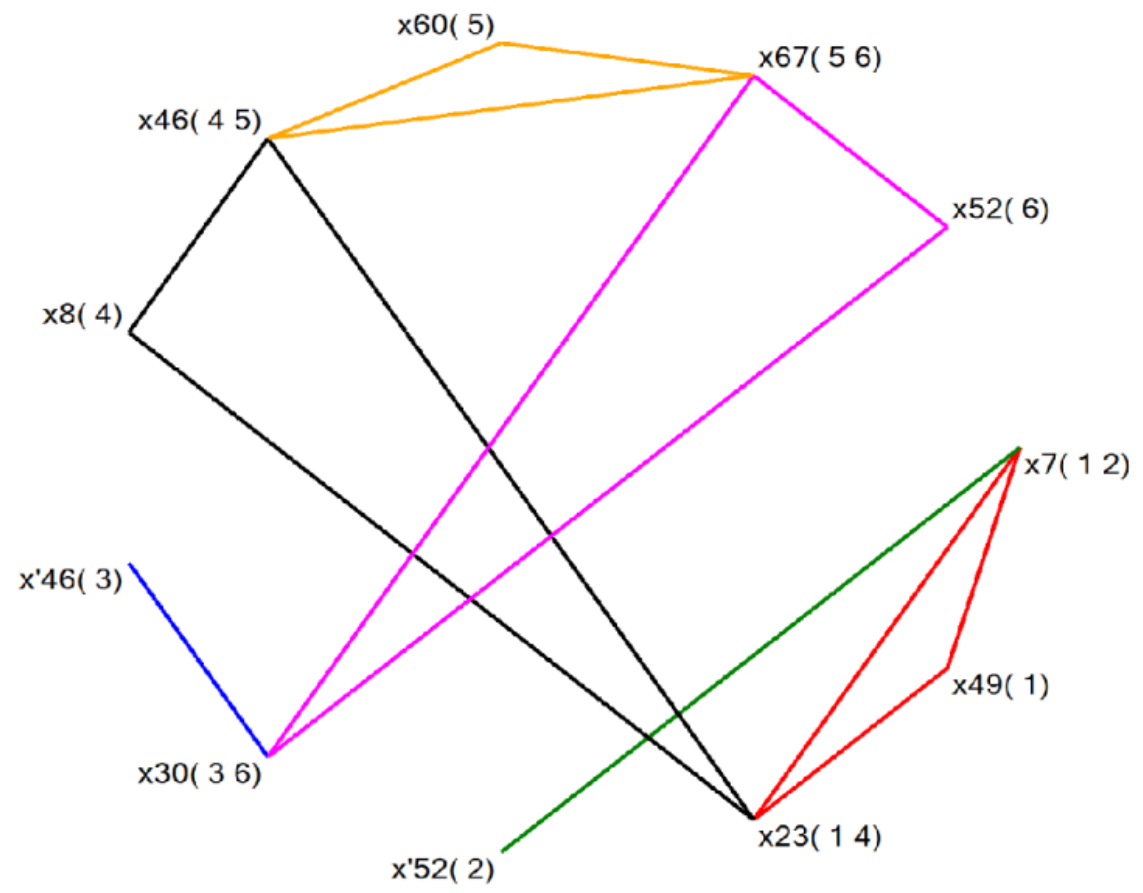

Figure 6. New counter model of functioning $\psi^{\prime}{ }_{a}$ propositional function $Z P_{x}$ after fission of prohibited counter figures.

New function $Z P_{x}$ :

$$
Z P_{x}\left(X_{1}, X_{2}, \ldots, X_{67}\right)^{\prime}=X_{7} X_{49} X_{23} V X_{7} X_{52}^{\prime} V X_{30} X_{46}^{\prime} V X_{8} X_{46} X_{23} V X_{46} X_{60} X_{67} V X_{30} X_{52} X_{67}
$$

For which the new model of $\psi_{a}^{\prime}$ takes the following form:

$$
\begin{gathered}
\Psi^{\prime}{ }_{a}=\left\langle M^{\prime}, R^{\prime}{ }_{2}, R^{\prime}{ }_{3}\right\rangle \\
\left.M^{\prime}=<X_{7}, X_{8}, X_{23}, X_{30}, X_{46}, X^{\prime}{ }_{46}, X_{49}, X_{52}, X_{52}^{\prime}, X_{60}, X_{67}\right\rangle \\
\left.R_{2}^{\prime}=\left\{X_{7} X_{52}^{\prime}\right\}_{2},\left\{X_{30} X_{46}^{\prime}\right\}_{3}\right\} \\
R_{3}^{\prime}=\left\{\left\{X_{7} X_{49} X_{23}\right\}_{1},\left\{X_{8} X_{46} X_{23}\right\}_{4},\left\{X_{46} X_{60} X_{67}\right\}_{5}\left\{X_{30} X_{52} X_{67}\right\}_{6}\right\}
\end{gathered}
$$

As a result of fusion it gets a new model of Figure 6, which corresponds to adequate Hasse diagram shown in Figure 7.

In fact, the costs of the presence of risk factors are most often higher than the ones, which are shown in income statements. It is for obtaining information on actual costs, which result from risk factors that the interpretation of the structural model is essential. On this basis it is known that the replica of variables in the following form were obtained: $X_{46}^{\prime}, X_{52}^{\prime}$. It has the consequences in the cost accounting of risk factors present in logistic processes. Table 4 shows that the costs of risk factors were put together on the basis of the new $\psi^{\prime} a$ model.

While comparing the total and actual costs of the appearance of risk factors, one can notice the importance of their correct calculation. After examining a small number of risk factors, the difference was more than PLN 1,700,000 (see Table 5), what gives the preliminary idea of the scale of the phenomenon. 


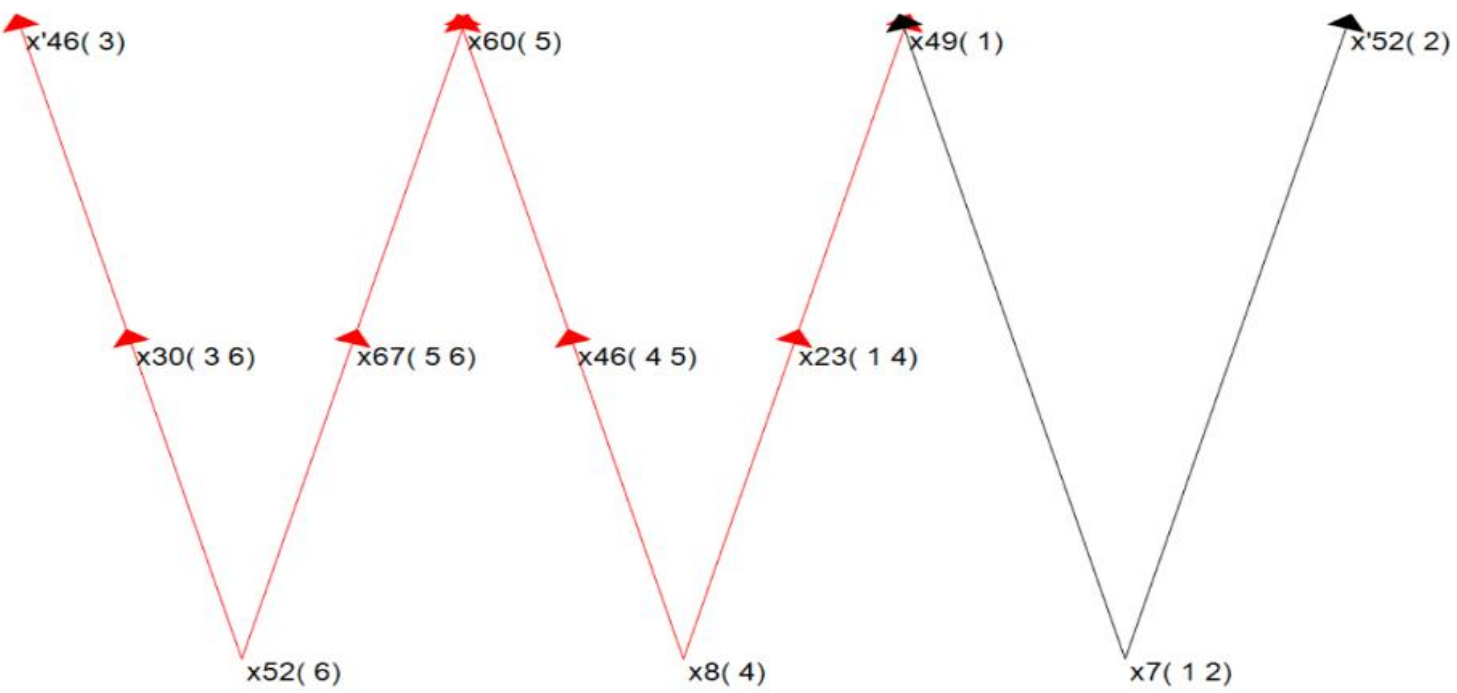

Figure 7. Structure model $\psi_{b}$ of propositional function $Z P_{x}$.

Table 4

The Analysis of the Costs of the Elimination of the Individual Risk Factors for the Selected Propositional Variables in the $\psi{ }^{\prime}{ }_{a}$ Operating Model of the $Z P^{\prime}{ }_{x}$ Function

\begin{tabular}{|c|c|c|c|c|}
\hline \multirow{2}{*}{$\begin{array}{l}\text { The area of the appearance of risk } \\
\text { factors }\end{array}$} & \multirow{2}{*}{ Propositional variable } & \multicolumn{2}{|c|}{$2012-2013$} & \multirow{2}{*}{ Quantity $\times$ cost } \\
\hline & & Quantity & Max cost & \\
\hline \multirow{3}{*}{ Supplies } & $X_{7}$ & 90 & 2,000 & 180,000 \\
\hline & $X_{49}$ & 49 & 5,100 & 249,900 \\
\hline & $X_{23}$ & 76 & 4,700 & 357,200 \\
\hline \multirow{3}{*}{ Production } & $X_{7}$ & 90 & 2,000 & 180,000 \\
\hline & $X_{52}$ & 180 & 5,200 & 936,000 \\
\hline & $X^{\prime}{ }_{52}$ & 180 & 5,200 & 936,000 \\
\hline \multirow{3}{*}{ Distribution } & $X_{30}$ & 159 & 1,500 & 238,500 \\
\hline & $X_{46}$ & 230 & 3,600 & 828,000 \\
\hline & $X_{46}^{\prime}$ & 230 & 3,600 & 828,000 \\
\hline \multirow{3}{*}{ Transport } & $X_{8}$ & 161 & 1,800 & 289,800 \\
\hline & $X_{46}$ & 230 & 3,600 & 828,000 \\
\hline & $X_{23}$ & 76 & 4,700 & 357,200 \\
\hline \multirow{3}{*}{ Storage } & $X_{46}$ & 230 & 3,600 & 828,000 \\
\hline & $X_{60}$ & 121 & 4,150 & 502,150 \\
\hline & $X_{67}$ & 99 & 2,859 & 283,041 \\
\hline \multirow{3}{*}{ Management logistics processes } & $X_{30}$ & 159 & 1,500 & 238,500 \\
\hline & $X_{52}$ & 180 & 5,200 & 936,000 \\
\hline & $X_{67}$ & 99 & 2,859 & 283,041 \\
\hline$\sum$ & & & & $9,279,332$ \\
\hline
\end{tabular}

Table 5

The Comparison of Total Costs and Actual Costs of the Elimination of Effects of Risk Factors

\begin{tabular}{ll}
\hline Balance & \\
\hline Total costs & Actual costs \\
\hline $7,515,332$ & $9,279,332$ \\
$1,764,000$ & \\
\hline
\end{tabular}


Demonstrating on the basis of the characterization made the cost difference show that not all resulting in the enterprise expenditure has been properly classified, which is not associated with the costs caused by risk factors. Demonstrating a difference instead of increasing the income start position results risk factors was (by the lack of proper identification) distributed on the income statement items such as cost of products sold, the value of goods and materials translating into cost of products, goods and materials. In addition, the costs caused by risk factors can be sought in the cost of sales, general and administrative expenses or profit (loss) on sales.

After this analysis, using a model based on the principle of characterization can be seen that the actual risk costs are higher than those reflected in the financial results in the profit and loss (if any are reported). The difference is already visible, taking into account only a few risk factors. Considering that during the tests reported in the enterprise 67 most adverse effects of repeated, the scale phenomenon is much greater. Not taking into account the actual cost of risk factors may have a significant influence on errors in decision-making, giving an incorrect picture of the financial situation. A false idea of the creation of value added, may consequently result in the deterioration of the conditions of the enterprise market.

\section{Conclusions}

Application of the principle of characterization is primarily associated with the demonstration of the actual costs actually incurred in connection with the occurrence of certain risk factors in logistics processes. This aspect has a strong practical value in decision-making process.

The functioning of the enterprise based on generating real value, determined by risk management is the basis for the creation of relationships on the market in all the areas of the manufacturing companies.

Analysis using the principle of characterization allows to organize activities related to the management of logistics processes, management added value and risk management. Additionally you can achieve synergies in the form of the fulfillment of the assumed levels of added value and action plans in the field of risk management for further periods.

On the basis of the costs associated with the presence of risk factors that the decisions concerning the expenses associated with securing against appearance of these risk factors in future should be taken. The choice and refining of the securing strategies against appearance of risk factors for needs of a given enterprise or the employment of a specialist in the field of the risk management is often very cost-consuming. The securing expenses against risk factors belong to the pool of alternative costs towards expenses associated with removing effects of their appearance. The answer to the question: "Shall it be secured or rather hoped that the risk factors will be avoided by simultaneous preparing funds for eliminating the effects?" requires accurate information concerning actual costs of the appearance of risk factors.

Making decisions based on underestimated data, you can come to the conclusion that spending on protection against risk factors is not relevant to the financial consequences of their occurrence. Carrying out the proposed analysis allows for a more precise eligibility of costs caused as a result of risk factors and their relationship with the achieved level of value added. In the face of the actual cost of the decisions in terms of broadly defined security expenditure prior to the occurrence of risk factors may be different from those taken on the basis of inaccurate information. 


\section{References}

Bowersox, D. J. (1987). Logistics strategic planning for the 1990s. Proceedings from the Council of Logistics Conference, Oak Brook.

Cooper, M. C., \& Ellram, L. M. (1993). Characteristics of supply chain management and the implication for purchasing and logistics strategy. International Journal of Logistics Management, 4(2), 13-24.

Giunipero, L. C., \& Brand, R. C. (1996). Purchasing's role in supply chain management. The International Journal of Logistics Management, 7(1), 29-38.

Gorbatov, V. A. (1979). Semantyczna teoria projektowania automatów (Semantic theory of automata design). Moskwa: Energia.

Hewitt, F. (1994). Supply chain redesign. The International Journal of Logistics Management, 5(2), 1-9.

Jenkinson, A. (1995). Valuing your customers: From quality relationships through database marketing. New York: McGraw-Hill.

Johnson, J. C., \& Wood, D. F. (1993). Contemporary logistics. New York: Macmillan Publishing Company.

Kulińska, E. (2009a). Wartość dla właścicieli a wartość dla klienta- metodyka analizy kosztów, (Value for owners and customer value: Cost analysis methodology). In W. Caputa, \& D. Szwajca (Eds.), Zarządzanie kosztami podmiotów gospodarczych (Cost management of business entities). Warsaw, pp. 221-230.

Kulińska, E. (2009b). Ryzyko procesów logistycznych w aspekcie tworzenia wartości dodanej—próba identyfikacji (The risk of logistic processes in the aspect of creation of the value added-An identification attempt) Logistyka, vol. 1 (pp. 36-39).

Kulińska, E. (2011). Aksjologiczny wymiar zarzadzania ryzykiem procesów logistycznych: Modele i eksperymenty ekonomiczne (Axiological dimension of risk management of logistics processes: Economic models and experiments). Opole: Oficyna Wydawnicza Politechniki Opolskiej (Opole University of Technology Publishing House).

Nazaretow, W. M., Kim, D. P., \& Krupa, T. (1991). Technical imitation of intellect. Warsaw: WNT.

Porter, M. E. (1985). Competitive advantage. New York: Free Press.

Porter, M. E. (1998). Competitive advantage: Creating and sustaining superior performance. New York: The Free Press.

Prahaland, C. K., \& Ramaswamy, V. (2005). Future of the competition: Co-creating of the unique value along with customers. Warsaw: PWE.

Schuderer, P. (1996). Prozeßorientierte Analyse und Rekonstruktion Logistischer Systeme: Konzeption-Methoden-Werkzeuge (Process-oriented analysis and reconstruction logistic systems: Conception-methods-tools). Wiesbaden: Gabler Verlag, Deutscher Universitäts-Verlag. 